\title{
HUMAN HYPOTHALAMUS SHOWS DIFFERENTIAL RESPONSES TO BASIC MOTIVATIONAL STIMULI-AN INVASIVE ELECTROPHYSIOLOGY STUDY
}

\author{
W. NAGER, ${ }^{a, b}$ J. K. KRAUSS, ${ }^{c}$ M. HELDMANN, ${ }^{d}$ \\ J. MARCO-PALLARES, ${ }^{e}$ H.-H. CAPELLE, ${ }^{c}$ G. LÜTJENS, ${ }^{c}$ \\ S. BOLAT, ${ }^{d}$ R. DENGLER ${ }^{b}$ AND T. F. MÜNTE ${ }^{d *}$ \\ ${ }^{a}$ Department of Neurology, Brandenburgklinik, 16321 Bernau-Wald- \\ siedlung, Germany \\ ${ }^{b}$ Department of Neurology, Medical School Hannover, 30623 Han- \\ nover, Germany \\ ${ }^{c}$ Department of Neurosurgery, Medical School Hannover, 30623 Han- \\ nover, Germany \\ ${ }^{d}$ Department of Neurology, University of Lübeck, Ratzeburger Allee \\ 160, 23538 Lübeck, Germany \\ ${ }^{e}$ Department of Ciències Fisiològiques, Faculty of Medicine, Campus \\ de Bellvitge-IDIBELL, University of Barcelona, 08907, Barcelona, \\ Spain
}

\begin{abstract}
The hypothalamus supports basic motivational behaviours such as mating and feeding. Recording directly from the posterior inferior hypothalamus in a male patient receiving a deep brain stimulation (DBS) electrode for the alleviation of cluster headache, we tested the hypothalamic response to different classes of motivational stimuli (sexually relevant: pictures of dressed and undressed women; pictures of food) and pictures of common objects as control. Averaged local field potentials (LFP) to sexually relevant stimuli were characterized by a biphasic significantly enhanced response (relative to objects; bootstrapping statistics) with a first phase starting at around $200 \mathrm{~ms}$ and a second phase peaking at around $600 \mathrm{~ms}$. Sexually relevant stimuli also showed a greatly enhanced positivity relative to other stimulus classes in surface event-related potentials in a group of 11 male control participants. It is suggested that the hypothalamus is involved in the recruitment of attentional resources by sexually relevant stimuli reflected in this surface positivity. In a second session, the response to food stimuli relative to objects was tested in two states: after fasting for $14 \mathrm{~h}$, LFPs to food and object stimuli showed significant differences in between 300 and $850 \mathrm{~ms}$, which disappeared after a full high-calorie meal, thus replicating classic studies in monkeys [Rolls et al., Brain Res (1976) 111:53-66]. The current data are the first to demonstrate hypothalamic responses to the sight of motivational stimuli in man and thus shows that recording from DBS electrodes might provide important information about the cognitive functions of subcortical structures. (c) 2011 IBRO. Published by Elsevier Ltd. All rights reserved.
\end{abstract}

Key words: hypothalamus, local field potentials, invasive recordings, motivational stimuli.

${ }^{*}$ Corresponding author. Tel: +49-451-5002926; fax: +49-451-5005457. E-mail address: Thomas.muente@neuro.uni-luebeck.de (T. F. Münte). Abbreviations: ANOVA, analysis of variance; $\mathrm{CH}$, cluster headache; DBS, deep brain stimulation; EEG, electroencephalogram; EOG, electrooculogram; ERP, event-related potential; LFP, local field potentials; $\mathrm{LH}$, lateral hypothalamus; $\mathrm{PIH}$, posterior inferior hypothalamus.
Our brain contains multiple systems that are devoted to basic motivational behaviors, such as mating, ingestion of fluids and food, and defence. In a widely accepted framework Swanson (2000) proposes that interconnected sets of nuclei in the hypothalamus and its brainstem extensions support the elaboration and control of such behaviors. Correspondingly, animals with lesions sparing the hypothalamus eat, drink, reproduce, and show defensive behaviours, while transsections below the hypothalamus severely impair these behaviors. The hypothalamus projects widely and indirectly to neocortex and forebrain limbic structures on the one hand and to brainstem motor pattern generators on the other hand (Kelley, 2004; Risold et al., 1997). The former projections may impact higher order behaviours, whereas the latter are responsible for automatic motor actions.

In the human, neuroimaging studies have shown the hypothalamus (together with other structures, such as the periaqueductal gray, and the insula) to be activated by sexually motivating pictures in healthy subjects (Karama et al., 2002; Mouras et al., 2003). Other work has demonstrated a hypothalamic response to food-related stimuli (Cornier et al., 2007; Killgore et al., 2003). For example, in normal volunteers, the hypothalamus showed marked activation to pictures of high calorie compared to low calorie foods suggesting that it is involved in the coding of motivational salience of food stimuli (Killgore et al., 2003).

Thus, there is evidence for an involvement of the hypothalamus in the regulation of reproductive and ingestive behaviours in the human, but owing to the low temporal resolution of imaging techniques the temporal dynamics of its neural responses remain largely unknown. In the present investigation we address these dynamics by recording electrophysiological activity from an electrode located in the posterior inferior hypothalamus $(\mathrm{PIH})$ in an awake human, while he viewed stimuli of motivational content. We took advantage of the fact that deep brain stimulation (DBS) of the PIH has been used in clinical studies for the treatment of chronic cluster headache $(\mathrm{CH}$, (Bussone et al., 2007; Leone, 2006)). $\mathrm{CH}$ is defined by severe unilateral headache of acute onset, accompanied by trigeminal autonomic dysfunction such as ipsilateral lacrimation (Headache Classification Committee of the International Headache Society, 2004; May, 2005). It shows striking seasonal variation and a relapsing-remitting course. Positron emission tomography (PET) studies have shown activation of the ipsilateral PIH during attacks (Sprenger et al., 2004; May et al., 1998) and increased grey matter density of the ipsilateral PIH has been described using voxel-based mor- 
phometry (May et al., 1999; May, 2009) suggesting a role of the hypothalamus in the etiology of $\mathrm{CH}$.

In the present study, we recorded local field potentials (LFP) in response to motivational stimuli (sexual and food) from a patient who had received a DBS electrode to the hypothalamus. Our aim was to establish the responsiveness of the human hypothalamus to these two kinds of basic motivational stimuli and to delineate its temporal course.

\section{EXPERIMENTAL PROCEDURES}

All procedures were approved by the ethical review board of the Medical School of Hannover.

\section{Patient}

The 52-year old man had suffered from right-sided chronic $\mathrm{CH}$ since age 41 and had received prolonged but unsuccessful courses of all standard treatments (including oxygen, sumatriptan, verapamil, corticosteroids). At the time of the recording the patient was on self-administered subcutaneous sumatriptan on demand. The patient fulfilled the published criteria to receive ipsilateral DBS (Leone, 2006).

\section{Control participants}

A group of 11 normal participants (all men, aged 24-35 years) with no history of neurological and psychiatric illness served as a control group to assess the electrophysiological effects of the stimuli.

\section{Stimuli and procedure}

In a first session 50 pictures per condition were presented to the patient with a stimulus duration of $3000 \mathrm{~ms}$ and an ISI of $4000 \mathrm{~ms}$. The four conditions showed dishes of food ("food"), undressed women in explicit postures ("undressed"), attractive but apparelled women ("dressed"), and objects like cars, flowers, houses or bridges ("objects"). The pictures were shown randomized across conditions. Because the stimuli had no uniform aspect ratios, the size of the pictures was adjusted ensuring a similar amount of pixels $(\sim 322620)$ per picture. The stimulus series was shown twice to the patient, who had no specific task but was instructed to watch the pictures in order to be able to answer questions about them afterwards. At the viewing distance of $90 \mathrm{~cm}$, pictures subtended approximately $6 / 9$ degrees of visual angle in height/width.

In a second session conducted on a different day, we were interested in the effect of satiety on the hypothalamic responses to food stimuli. The stimulus series therefore only comprised items of the "food" and "objects" categories (50 items of each category). The session was split in two parts. The first recording took place at $8 \mathrm{AM}$, when the patient had been fasting since $6 \mathrm{PM}$ of the previous day. Subsequent to this recording the patient ordered his favourite meal and was tested again when he was satiated.

Pictures were assessed by a group of 10 men, all natives of Germany, aged 35-51. Pictures were presented on a computerscreen and participants proceeded from picture to picture by pressing a button on a computer-keyboard at their own pace. For food and object pictures, participants had to rate arousal (0 [not arousing] to 10 [highly arousing]) and valence ( -5 [negative] to 5 [positive]), whereas for the pictures depicting undressed and dressed women they had to rate sexual attractiveness ( 0 [not sexually attractive] to 10 [highly attractive]). The mean ratings (SEM in brackets) were: food: arousal $4.93(0.18)$, valence -0.09 (0.54); object: arousal $3.87(0.55)$, valence $0.50(0.17)$; women undressed: arousal $6.74(0.46)$, valence $1.72(0.54)$, sexual at- tractiveness $6.68(0.55)$; women dressed: arousal $4.67(0.62)$, valence $1.10(0.46)$, sexual attractiveness $4.04(0.68)$.

\section{Electrophysiological recording/patient}

The target in the PIH was defined by CT-stereotactic surgery refined by microelectrode recording. There were no surgical side effects. The cables attached to the DBS electrode (Medtronic Inc, Minneapolis, MN, USA, model 3389) were externalized for several days for test stimulation before the pacemaker was implanted. Accurate placement of the electrode in the PIH was confirmed by postoperative stereotactic CT imaging directly after the surgical procedure. Details of the procedure have been published elsewhere (Bartsch et al., 2008). The DBS electrode hosts four contacts within the target structure. We mainly report recordings between the two contacts with the greatest distance (centers spaced $6 \mathrm{~mm}$ apart). In addition we also obtained surface EEG activity (Fz, F3, F4, Pz, P3, P4 referenced to the right mastoid process). Data were sampled at 1000 points/s and data analysis was performed using EEG-Lab (Delorme and Makeig, 2004) and ERP-Lab (http://www.erpinfo.org/erplab/erplab-toolbox) software. To assess differences between conditions in single patient data, we employed a nonparametric statistical test implemented in Matlab as suggested in Maris and Oostenveld (2007). In brief, given two experimental conditions (condition A and condition $\mathrm{B}$ ) we first computed the $t$ statistic for them by using the mean and standard deviation among trials. We then randomly assigned the trials to one of the conditions maintaining the same number of trials per condition as in the experimental dataset and computed the test statistic for this random partition. We repeated this procedure 1000 times to obtain the histogram of the distribution of the single trials and calculated the proportion of random partition with a $t$ statistic greater than the one in the experimental condition. This proportion will be the $P$-value of our effect. If the $P$-value was smaller than the critical alpha level $(0.05)$ the two conditions were considered to be significantly different. We employed this procedure for successive $20 \mathrm{~ms}$ time-windows from the onset of the stimulus until $1000 \mathrm{~ms}$ poststimulus.

Event-related potentials (ERPs) were obtained in the same way as described for the control group. For visualization, ERPs were low-passed filtered with a $15 \mathrm{~Hz}$ filter.

\section{Electrophysiological recording/control participants}

The control-participants were shown the same stimulus series that was presented in session 1 of the patient. The electroencephalogram was recorded from the scalp from 29 standard positions (Fp1/2, F3/4, C3/4, T3/4, T5/6, P3/4, O1/2, F7/8, Fz, Cz, Pz, $\mathrm{Fc} 3 / 4, \mathrm{FT} 7 / 8, \mathrm{Cp} 3 / 4, \mathrm{TP} 7 / 8, \mathrm{PO} / 4$ ). Biosignals were re-referenced off-line to the mean of the activity at the two mastoid leads. Vertical eye movements were monitored with an electrode at the infraorbital ridge of the left eye. Electrode impedances were kept below $5 \mathrm{k} \Omega$. The electrophysiological signals were filtered with a bandpass of $0.1-50 \mathrm{~Hz}$ and digitized at a rate of $250 \mathrm{~Hz}$. To remove eye-blink artifacts, data were subjected to blind source separation as described by Joyce et al. (2004).

Event-related potentials were averaged for an epoch length of $1024 \mathrm{~ms}$ starting $100 \mathrm{~ms}$ before the onset of the stimulus. ERPs were baseline-corrected with the mean amplitude between -100 and $0 \mathrm{~ms}$ set to zero. We quantified the differences between the different conditions using non-parametric statistics. These were performed similar to the procedure described above for the patient. Instead of single trials the average of each subject and each condition was entered into the statistical analysis. Again, 1000 repetitions per test were performed for successive $20 \mathrm{~ms}$ time windows from stimulus onset until $900 \mathrm{~ms}$ post-stimulus. 
A

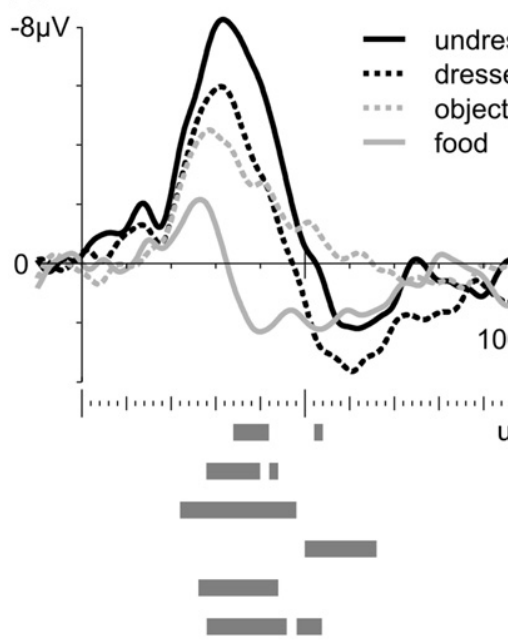

B

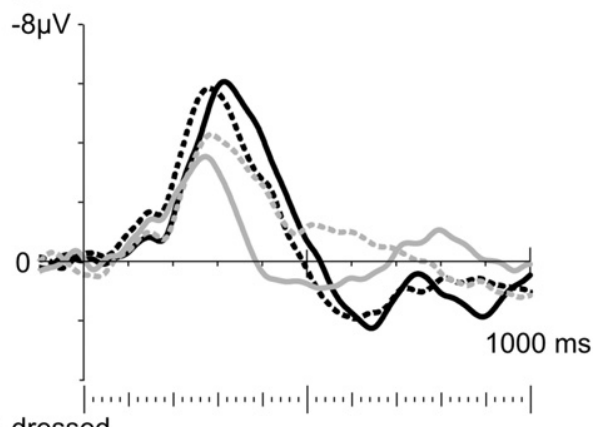

undressed vs. dressed undressed vs. object undressed vs. food dressed vs. object dressed vs. food object vs. food

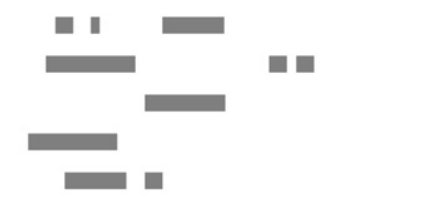

Fig. 1. Average LFPs from the patient, session 1. Depicted are bipolar derivations between contacts 0 and 3 of the DBS electrode. (A) Responses from the first half of the session containing no repetitions of stimuli. Robust differences are seen between the different stimulus classes. Sexually relevant stimuli, in particular pictures of undressed women gave rise to an enhanced biphasic response starting around $200 \mathrm{~ms}$. The grey bars at the bottom mark time windows with significant differences between responses to the different stimulus classes $(P<0.05$, bootstrapping statistics). (B) Recordings from the entire session (including stimulus repetitions). Again, differences between different stimulus classes were obtained.

\section{RESULTS}

\section{Patient}

The averaged LFP from session 1 are illustrated for the first half of the session (i.e. first presentation of each stimulus), and for the entire session on the left and right panel of Fig. 1. Depicted are the bipolar recordings between contacts 0 and 3 of the DBS-electrode. LFPs to pictures of dressed and undressed women are clearly differentiated from the other two stimulus categories by an initial negativity between 200 and about $450 \mathrm{~ms}$ and a subsequent positivity from $500 \mathrm{~ms}$ onwards. The shaded grey areas below the waveforms depict those timestretches in which the bootstrapping method described in the method section revealed significant differences between pairs of stimulus categories. It is noteworthy, that for the first presentation of the stimulus-series a marked difference between stimulus categories dressed and undressed was present which was no longer significant when the entire session was considered. This suggests a habituation of the response to the stimulus category undressed. Data from recordings between contacts 0 and 1,0 and 2 and 0 and 3 are contrasted in Fig. 2. There was no polarity inversion and the amplitude of the responses was largest in the bipolar recording between contacts 0 and 3 and smallest between 0 and 1 . To illustrate the time-course of the effects, LFPs to stimulus categories dressed, undressed, and object are shown on a longer $3 \mathrm{~s}$ time-scale in Fig. 3. Clearly, the major differences between stimulus categories are seen in the first second after presentation. Fig. 4 illustrates the surface ERPs of the patient from electrode $\mathrm{Pz}$. These recordings were rather noisy due to the postoperative stress.

In session 2, only food and object stimuli were presented. Fig. 5 shows the LFPs to these types of stimuli after prolonged fasting of the patient. Visual inspection suggests clear differences between the LFPs which are corroborated by the bootstrapping statistics (shaded grey areas mark significant differences). For the second part of the session, conducted after a hearty meal, waveform differences were no longer present.

\section{Control participants}

As surface ERPs are notoriously blind to activity in subcortical structures, the purpose of the recordings in the control participants was therefore mainly to assess the

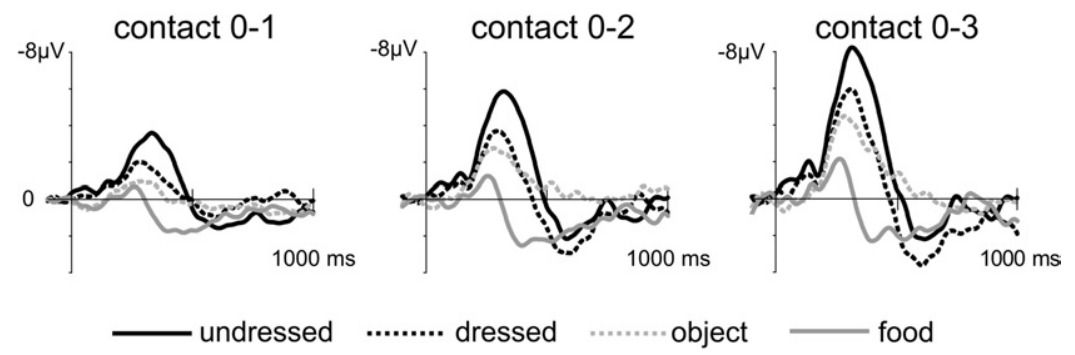

Fig. 2. LFP from session 1, bipolar derivations. Shown are several bipolar derivations from the DBS electrode. Contacts 0 and 3 have the greatest distance $(6 \mathrm{~mm})$. 


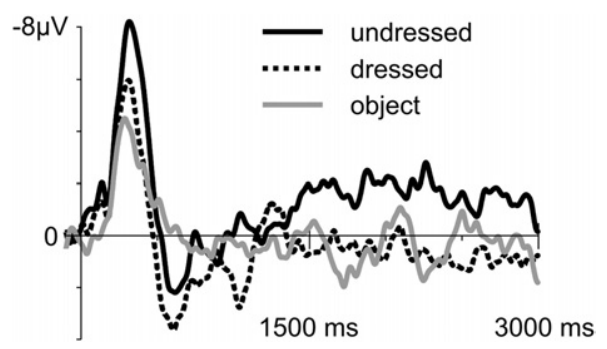

Fig. 3. Average LFPs on a longer time scale. These recordings demonstrate that differences between sexually relevant and control stimuli can be observed mainly within the first second after stimulus presentation.

impact of the motivational stimuli on late ERP components which are known to reflect aspects of attentional processing. Fig. 6 illustrates the group average ERPs from three midline electrodes. Marked differences between the different stimulus classes are readily apparent in the waveforms: stimulus category "undressed" was associated with a high amplitude positivity with a maximum at approximately $400 \mathrm{~ms}$, which was less pronounced for stimulus category "dressed." Stimulus categories "food" and "object" on the other hand showed a frontal negativity. The differences between conditions were confirmed by nonparametric statistics and are marked in Fig. 6.

Finally, the ERPs from the control participants were computed separately for the first and second half of the session and illustrated in Fig. 7. Unlike in the depth recordings of the patient, no attenuation was seen from the first to the second half of the session.

\section{DISCUSSION}

In the current single patient study we took advantage of the fact that the PIH has been identified recently as a promising target for the treatment of cluster headache (Bartsch et al., 2008; Bussone et al., 2007; Leone et al., 2005) and investigated the hypothalamic response to basic motivational stimuli by recording from electrodes placed for DBS

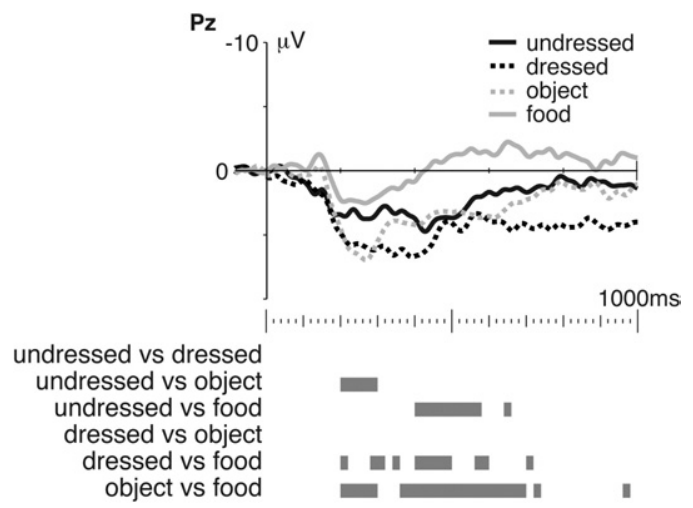

Fig. 4. Surface activity from the patient recorded in parallel to the depth recording. As in the control sample but to a much lesser extent, responses to sexually relevant stimuli show the most pronounced parietal positive response. The grey bars at the bottom mark time windows with significant differences between responses to the different stimulus classes $(P<0.05$, bootstrapping statistics).

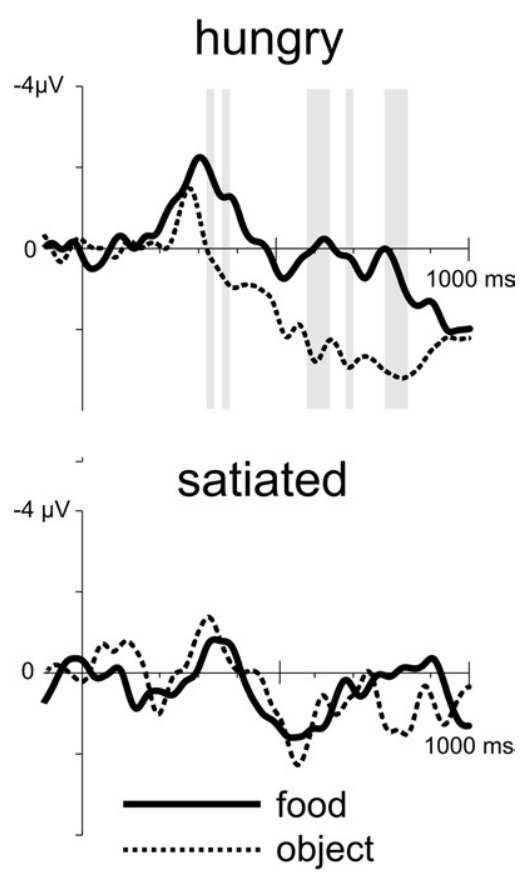

Fig. 5. Average LFPs from session 2. Responses to food and object stimuli show marked differences in several time-windows between 300 and $850 \mathrm{~ms}$ when the patient was hungry. These differences are no longer present after the patient had a high calorie meal.

treatment. Importantly, and in accord with our expectations, we observed changes in the averaged LFP as a function of stimulus category.

\section{Sexually relevant stimuli}

With regard to the sexually relevant stimulus categories, pictures of dressed and, to a greater extent, undressed women led to an enhanced response in the hypothalamus starting around $200 \mathrm{~ms}$ relative to the other stimulus categories. Interestingly, upon repetition of the stimuli the amplitude difference between LFP to pictures of dressed and undressed women disappeared suggesting habituation, while the differences to the other stimuli were preserved. The high motivational value of the stimuli depicting dressed and undressed women is corroborated by the large positive posterior ERP responses to these stimulus categories in the control participants which showed a slight, but non-significant attenuation over the course of the experiment (Fig. 7). Indeed, van Lankveld and Smulders (2008) recently found a similar amplification of a parietal positive component to sexual pictorial stimuli in comparison to pictures depicting high energy sports. Importantly, stimulus categories had been matched for arousal and valence in the van Lankveld and Smulders study. It was suggested that the sexual pictorial stimuli captured more attentional resources indexed by the ERP positivity (Polich and Kok, 1995), because of their motivational relevance. Indeed, in the model of "motivated attention" (Lang et al., 1997) it is stated that evolutionarily relevant stimuli are more capable than other types of stimuli to trigger motivational systems. What the present data 


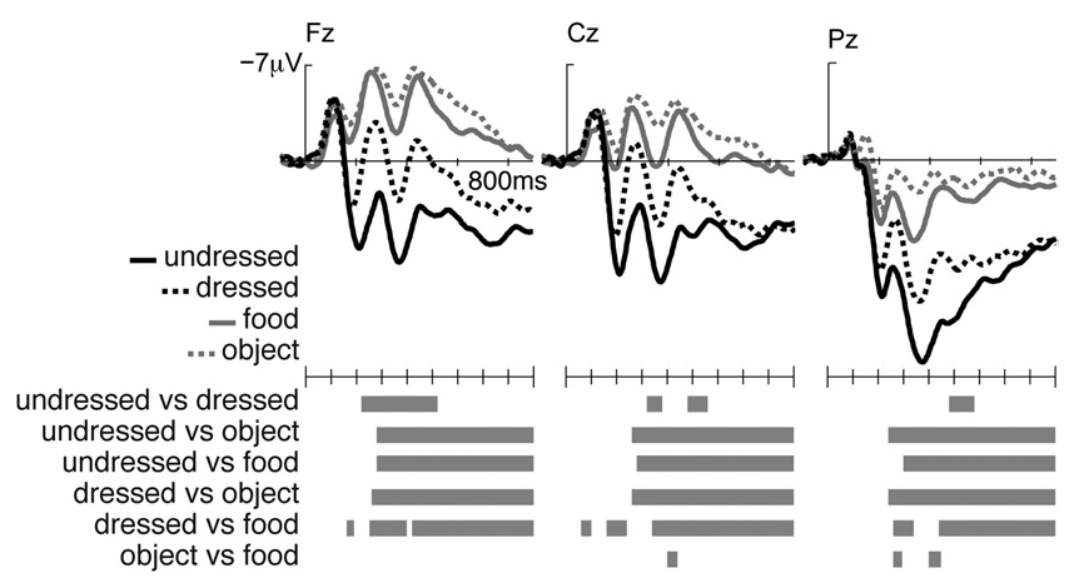

Fig. 6. Grand average surface event-related potentials from 11 male control participants. Responses to pictures of undressed and, less so, to dressed women show a high amplitude positivity with a parietal maximum (electrode Pz). Pictures to object and food stimuli showed only a small positive response at $\mathrm{Pz}$ under the passive viewing conditions used in this study but a marked frontal negativity. The grey bars at the bottom mark time windows with significant differences between responses to the different stimulus classes $(P<0.05$, bootstrapping statistics).

imply, then, is that the hypothalamus reacts very fast to sexually motivating stimuli. It may therefore well be involved in the recruitment of attentional resources which are reflected in the increased late positivity in the surface recordings. Because the hypothalamus is reciprocally connected to the locus coeruleus (among other brainstem structures) (Gao and Horvath, 2007; Horvath et al., 1999) and the late positivity in the ERP has been shown to be driven by noradrenergic activity of the locus coeruleus (Nieuwenhuis et al., 2005; Pineda et al., 1989), this might be the pathway by which attentional resources are recruited by the hypothalamus. It is interesting to note, that the surface ERPs of the patient (Fig. 4) showed less differences between pictures of dressed and undressed women than those of the control participants in particular with regard to the parietal positivity. This raises the question, whether this could be an index of a general dysfunction of the hypothalamus in the patient. It has to be noted, however, that the surface recordings in the patient were rather noisy due to movement artefacts.

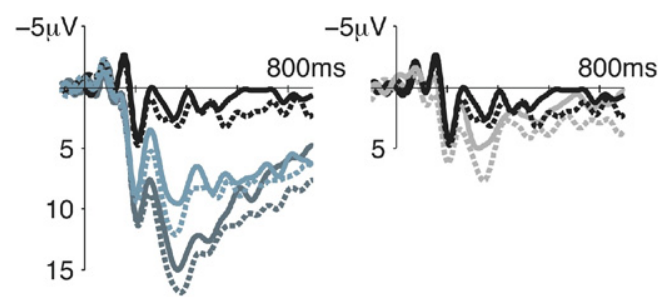

1st half: —undressed — dressed — food - object

2nd half: ..... undressed $\ldots . .$. dressed.... food ..... object

Fig. 7. Split half analysis in control participants. To assess stability of the response to the stimuli, the first and the second half of the ERP session of the healthy controls were averaged separately. Unlike the patient, normal control participants showed a rather stable response. Please note, however, that the patient's session was twice as long (i.e. 100 pictures per condition; controls: 50 pictures per condition) and that the patient saw the same pictures twice during the session, whereas the controls only saw each picture once. For interpretation of the references to color in this figure legend, the reader is referred to the Web version of this article.
Examination of the hypothalamic response to picture stimuli on a longer time scale suggests that it is mainly characterized by a biphasic response with the first negative component peaking at approximately $400 \mathrm{~ms}$ and the second positive peak having a maximum around $550 \mathrm{~ms}$.

The question arises, as to where the LFP to sexually relevant stimuli come from. Evidence from rodents shows that the ventromedial nucleus, the ventral premammillary nucleus and the medial preoptic nucleus are core parts of a circuit mediating reproductive behavior (Simerly, 1998). It is quite conceivable that contacts placed in the posterior inferior hypothalamus pick up activity arising from the ventromedial nucleus which lies in close proximity. This notion is corroborated by the fact that we did not observe a polarity-inversion but a gradual amplitude increment when different bipolar derivations from the hypothalamic contacts were compared (Fig. 2).

\section{Food stimuli}

The hypothalamus is involved in the regulation of energy intake and feeding behavior (Oomura, 1973; Horvath and Diano, 2004; Grossman, 1975; Swanson, 2000; Kelley, 2004) and lesions involving different parts of the hypothalamus may produce hyper- or hypophagia (Hetherington and Ranson, 1942; Mayer and Marshall, 1956). Consequently, it has been suggested that the ventromedial hypothalamus serves as a "satiety" center, whereas the lateral hypothalamus serves a complementary function as a "hunger" center. Whereas the role of the hypothalamus in the homeostatic regulation of food intake driven by metabolic signals from the periphery and mediated by a number of different neuropeptides is well recognized (Horvath and Diano, 2004), the hypothalamus also appears to responds to sensory input related to food stimuli. Of particular relevance for the present investigation are demonstrations of the responsiveness of single cells in the lateral hypothalamus (LH) to the sight of food stimuli in monkeys (Burton et al., 1976; Rolls et al., 1976; Ono et al., 1981) and sheep (Mungarndee et al., 2002). Interestingly, the response la- 
tency of such neurons in the monkey is 150-200 ms, which corresponds well to the present findings to food stimuli (c.f. Fig. 4), and the activity of these neurons predicted the motor response of the animal to obtain food (Rolls et al., 1979). In addition, feeding monkeys to satiety for a certain type of food decreased the responses of $\mathrm{LH}$ neurons to the sight and/or taste of this particular food but not for other foods on which the monkey had not been satiated ("sensory-specific satiety," Rolls et al., 1986). The current finding of a decrease of the difference between the responses to food and object stimuli in the satiated state suggests that a similar neural mechanism is also present in the human hypothalamus. Indeed, it has recently been demonstrated using functional MRI that the response of the hypothalamus to pictures of high calorie food stimuli was greatly reduced after participants were overfed (Cornier et al., 2007).

\section{CONCLUSIONS}

The present investigation is the first to demonstrate phasic modulations of the LFP in response to motivational stimuli from the hypothalamus of an awake human. The robust differences between the LFP to different stimulus classes are in accord with previous neuroimaging and animal studies. These results as well as other recent investigations using similar methods in other DBS target structures suggest that recording of LFP during or after the implantation of electrodes may provide an important new window on brain functions in humans (Cohen et al., 2009a,b,c; Klostermann et al., 2006; Münte et al., 2008, 2007) and may complement neuroimaging investigation by adding temporal information.

Obviously, the current study has several limitations: first, only one patient has been studied owing to the scarcity of cluster headache patients eligible for this procedure. However, the posterior hypothalamus has been considered in a number of other neuropsychiatric conditions, including epilepsy (Franzini et al., 2008), obesity (Halpern et al., 2008) and aggression (Kuhn et al., 2008). Thus, more patients will likely be available in the future. Second, it would have been desirable to test hypothalamic responses more systematically. For example, the hypothalamus has also been implicated in the regulation of aggression (Toth et al., 2010), suggesting that aggression relevant stimuli might be worth to study. Also, with regard to food stimuli a variation of the calorie content or a grouping of stimuli according to the personal preferences of the patient would have been desirable. Time limitations did not allow this in the current study.

Acknowledgments-T.F.M. is supported by the DFG (SFB 779, project A5). J.M.P. was the recipient of an Alexander-von-Humboldt Fellowship. He is currently supported by the Ramon-y-Cajal program of the Spanish government.

\section{REFERENCES}

Bartsch T, Pinsker MO, Rasche D, Kinfe T, Hertel F, Diener HC, Tronnier V, Mehdorn HM, Volkmann J, Deuschl G, Krauss JK
(2008) Hypothalamic deep brain stimulation for cluster headache: experience from a new multicase series. Cephalalgia 28:285-295.

Burton MJ, Rolls ET, Mora F (1976) Effects of hunger on the responses of neurons in the lateral hypothalamus to the sight and taste of food. Exp Neurol 51:668-677.

Bussone G, Franzini A, Proietti CA, Mea E, Curone M, Tullo V, Broggi G, Casucci G, Bonavita V, Leone M (2007) Deep brain stimulation in craniofacial pain: seven years' experience. Neurol Sci 28 (Suppl 2): S146-S149.

Cohen MX, Axmacher N, Lenartz D, Elger CE, Sturm V, Schlaepfer TE (2009a) Good vibrations: cross-frequency coupling in the human nucleus accumbens during reward processing. J Cogn Neurosci 21:875-889.

Cohen MX, Axmacher N, Lenartz D, Elger CE, Sturm V, Schlaepfer TE (2009b) Neuroelectric signatures of reward learning and decisionmaking in the human nucleus accumbens. Neuropsychopharmacology 34:1649-1658.

Cohen MX, Axmacher N, Lenartz D, Elger CE, Sturm V, Schlaepfer TE (2009c) Nuclei accumbens phase synchrony predicts decisionmaking reversals following negative feedback. J Neurosci 29: 7591-7598.

Cornier MA, Von Kaenel SS, Bessesen DH, Tregellas JR (2007) Effects of overfeeding on the neuronal response to visual food cues. Am J Clin Nutr 86:965-971.

Delorme A, Makeig S (2004) EEGLAB: an open source toolbox for analysis of single-trial EEG dynamics. J Neurosci Methods 134: $9-21$.

Franzini A, Messina G, Marras C, Villani F, Cordella R, Broggi G (2008) Deep brain stimulation of two unconventional targets in refractory non-resectable epilepsy. Stereotact Funct Neurosurg 86:373-381.

Gao Q, Horvath TL (2007) Neurobiology of feeding and energy expenditure. Annu Rev Neurosci 30:367-398.

Grossman SP (1975) Role of the hypothalamus in the regulation of food and water intake. Psychol Review 82:200-224.

Halpern CH, Wolf JA, Bale TL, Stunkard AJ, Danish SF, Grossman M, Jaggi JL, Grady MS, Baltuch GH (2008) Deep brain stimulation in the treatment of obesity. J Neurosurg 109:625-634.

Headache Classification Committee of the International Headache Society (2004) The International Classification of Headache Disorders: 2nd edition. Cephalalgia 24:9-160.

Hetherington AW, Ranson SW (1942) The relation of various hypothalamic lesions to adiposity in the rat. J Comp Neurol 76: 475-499.

Horvath TL, Diano S (2004) The floating blueprint of hypothalamic feeding circuits. Nat Rev Neurosci 5:662-667.

Horvath TL, Peyron C, Diano S, Ivanov A, ston-Jones G, Kilduff TS, van Den Pol AN (1999) Hypocretin (orexin) activation and synaptic innervation of the locus coeruleus noradrenergic system. J Comp Neurol 415:145-159.

Joyce CA, Gorodnitsky IF, Kutas M (2004) Automatic removal of eye movement and blink artifacts from EEG data using blind component separation. Psychophysiology 41:313-325.

Karama S, Lecours AR, Leroux JM, Bourgouin P, Beaudoin G, Joubert $S$, Beauregard M (2002) Areas of brain activation in males and females during viewing of erotic film excerpts. Hum Brain Mapp 16:1-13.

Kelley AE (2004) Ventral striatal control of appetitive motivation: role in ingestive behavior and reward-related learning. Neurosci Biobehav Rev 27:765-776.

Killgore WD, Young AD, Femia LA, Bogorodzki P, Rogowska J, Yurgelun-Todd DA (2003) Cortical and limbic activation during viewing of high- versus low-calorie foods. Neuroimage 19:1381-1394.

Klostermann F, Wahl M, Marzinzik F, Schneider GH, Kupsch A, Curio G (2006) Mental chronometry of target detection: human thalamus leads cortex. Brain 129:923-931.

Kuhn J, Lenartz D, Mai JK, Huff W, Klosterkoetter J, Sturm V (2008) Disappearance of self-aggressive behavior in a brain-injured pa- 
tient after deep brain stimulation of the hypothalamus: technical case report. Neurosurgery 62:E1182.

Lang PJ, Bradley MM, Cuthbert BN (1997) Motivated attention: affect, activation, and action. In: Attention and orienting: sensory and motivational processes (Lang PJ, Simons RF, Balaban MT, eds), pp 97-135. Hillsdale, NJ: Lawrence Erlbaum Associates.

Leone M (2006) Deep brain stimulation in headache. Lancet Neurol 5:873-877.

Leone M, Franzini A, Felisati G, Mea E, Curone M, Tullo V, Broggi G, Bussone G (2005) Deep brain stimulation and cluster headache. Neurol Sci 26 (Suppl 2):s138-s139.

Maris E, Oostenveld R (2007) Nonparametric statistical testing of EEG- and MEG-data. J Neurosci Methods 164:177-190.

May A (2005) Cluster headache: pathogenesis, diagnosis, and management. Lancet 366:843-855.

May A (2009) Morphing voxels: the hype around structural imaging of headache patients. Brain 132:1419-1425.

May A, Ashburner J, Buchel C, McGonigle DJ, Friston KJ, Frackowiak RS, Goadsby PJ (1999) Correlation between structural and functional changes in brain in an idiopathic headache syndrome. Nat Med 5:836-838.

May A, Bahra A, Buchel C, Frackowiak RS, Goadsby PJ (1998) Hypothalamic activation in cluster headache attacks. Lancet 352 : 275-278.

Mayer J, Marshall NB (1956) Specificity of gold thioglucose for ventromedial hypothalamic lesions and hyperphagia. Nature 178:1399-1400.

Mouras H, Stoleru S, Bittoun J, Glutron D, Pélégrini-Issac M, Paradis AL, Burnod $Y$ (2003) Brain processing of visual sexual stimuli in healthy men: a functional magnetic resonance imaging study. Neuroimage 20:855-869.

Mungarndee SS, Baldwin BA, Chindadoungratana C, Kotchabhakdi N (2002) Hypothalamic and zona incerta neurons in sheep, initially only responding to the sight of food, also respond to the sight of water after intracerebroventricular injection of hypertonic saline or angiotensin II. Brain Res 925:204-212.

Münte TF, Heldmann M, Hinrichs H, Marco-Pallares J, Kramer UM, Sturm V, Heinze HJ (2007) Nucleus accumbens is involved in human action monitoring: evidence from invasive electrophysiological recordings. Front Hum Neurosci 1:11.
Münte TF, Heldmann M, Hinrichs H, Marco-Pallares J, Kramer UM, Sturm V, Heinze HJ (2008) Contribution of subcortical structures to cognition assessed with invasive electrophysiology in humans. Front Neurosci 2:72-78.

Nieuwenhuis S, ston-Jones G, Cohen JD (2005) Decision making, the P3, and the locus coeruleus-norepinephrine system. Psychol Bull 131:510-532.

Ono T, Nishino H, Sasaki K, Fukuda M, Muramoto KI (1981) Monkey lateral hypothalamic neuron response to sight of food, and during bar press and ingestion. Neurosci Lett 21:99-104.

Oomura Y (1973) Central mechanism of feeding. Adv Biophys 5: 65-142.

Pineda JA, Foote SL, Neville HJ (1989) Effects of locus coeruleus lesions on auditory, long-latency, event-related potentials in monkey. J Neurosci 9:81-93.

Polich J, Kok A (1995) Cognitive and biological determinants of P300: an integrative review. Biol Psychol 41:103-146.

Risold PY, Thompson RH, Swanson LW (1997) The structural organization of connections between hypothalamus and cerebral cortex. Brain Res Brain Res Rev 24:197-254.

Rolls ET, Burton MJ, Mora F (1976) Hypothalamic neuronal responses associated with the sight of food. Brain Res 111:53-66.

Rolls ET, Murzi E, Yaxley S, Thorpe SJ, Simpson SJ (1986) Sensoryspecific satiety: food-specific reduction in responsiveness of ventral forebrain neurons after feeding in the monkey. Brain Res 368:79-86.

Rolls ET, Sanghera MK, Roper-Hall A (1979) The latency of activation of neurones in the lateral hypothalamus and substantia innominata during feeding in the monkey. Brain Res 164:121-135.

Simerly RB (1998) Organization and regulation of sexually dimorphic neuroendocrine pathways. Behav Brain Res 92:195-203.

Sprenger T, Boecker H, Tolle TR, Bussone G, May A, Leone M (2004) Specific hypothalamic activation during a spontaneous cluster headache attack. Neurology 62:516-517.

Swanson LW (2000) Cerebral hemisphere regulation of motivated behavior. Brain Res 886:113-164.

Toth M, Fuzesi T, Halasz J, Tulogdi A, Haller J (2010) Neural inputs of the hypothalamic "aggression area" in the rat. Behav Brain Res 215:7-20.

van Lankveld JJ, Smulders FT (2008) The effect of visual sexual content on the event-related potential. Biol Psychol 79:200-208. 